\title{
Detecting multiple DNA human profile from a mosquito blood meal
}

\author{
K.C.N. Rabêlo ${ }^{1,4}$, C.M.R. Albuquerque ${ }^{2}$, V.B. Tavares ${ }^{3}$, S.M. Santos ${ }^{4}$, \\ C.A. Souza ${ }^{4}$, T.C. Oliveira ${ }^{1,4}$, R.R. Moura ${ }^{1}$, L.A.C. Brandão ${ }^{6}$ and S. Crovella ${ }^{1,5}$ \\ ${ }^{1}$ Laboratório de Imunopatologia Keizo Asami, \\ Universidade Federal de Pernambuco, Recife, PE, Brasil \\ ${ }^{2}$ Departamento de Zoologia, Universidade Federal de Pernambuco, \\ Recife, PE, Brasil \\ ${ }^{3}$ Laboratório de Endemias, Laboratório Central de Saúde Pública de Pernambuco, \\ Recife, PE, Brasil \\ ${ }^{4}$ Laboratório de Perícia e Pesquisa em Genética Forense, \\ Secretaria de Defesa Social de Pernambuco, Recife, PE, Brasil \\ ${ }^{5}$ Departamento de Genética, Universidade Federal de Pernambuco, \\ Recife, PE, Brasil \\ ${ }^{6}$ Departamento de Patologia da Universidade Federal de Pernambuco, \\ Recife, PE, Brasil \\ Corresponding author: K.C.N. Rabêlo \\ E-mail: kaynaracecilia@yahoo.com.br
}

Genet. Mol. Res. 15 (3): gmr.15037547

Received August 28, 2015

Accepted December 7, 2015

Published August 26, 2016

DOI http://dx.doi.org/10.4238/gmr.15037547

Copyright (C) 2016 The Authors. This is an open-access article distributed under the terms of the Creative Commons Attribution ShareAlike (CC BY-SA) 4.0 License

\begin{abstract}
Criminal traces commonly found at crime scenes may present mixtures from two or more individuals. The scene of the crime is important for the collection of various types of traces in order to find the perpetrator of the crime. Thus, we propose that hematophagous mosquitoes found at crime scenes can be used to perform genetic testing of human blood and aid in suspect investigation. The aim of
\end{abstract}


the study was to obtain a single Aedes aegypti mosquito profile from a human DNA mixture containing genetic materials of four individuals. We also determined the effect of blood acquisition time by setting time intervals of 24,48 , and $72 \mathrm{~h}$ after the blood meal. STR loci and amelogenin were analyzed, and the results showed that human DNA profiles could be obtained from hematophagous mosquitos at $24 \mathrm{~h}$ following the blood meal. It is possible that hematophagous mosquitoes can be used as biological remains at the scene of the crime, and can be used to detect human DNA profiles of up to four individuals.

Key words: Mosquito blood meal; DNA mixtures; Forensic DNA; Aedes aegypti

\section{INTRODUCTION}

Hematophagy in mosquito vectors influences characteristics that affect reproductive functions (Attardo et al., 2005), disease transmission (Scott and Takken, 2012), vector control (Harrington et al., 2014), and even forensic entomology (Spitaleri et al., 2006). Several mosquito species such as Aedes aegypti (Xue et al. 1995; Scott et al., 1993a,b, 2000; Reyes-Villanueva, 2004), Aedes albopictus (Delatte et al., 2010), and the Anopheles species (Edman and Downe 1964; Boreham and Garrett-Jones, 1973; Burkot et al. 1988; Conway and McBride, 1991) require their blood meals as a consequence of physiological traits (anautogeny) (Clements, 1999). In response to host defense responses, several traits have evolved in the mosquito to prevent feeding disruption (Conway and McBride, 1991; Clements, 1999). Such behaviors have many important implications. Multiple feedings in a gonotrophic cycle allow mosquitos to increase the number of eggs laid (Amerasinghe and Amerasinghe, 1999; Charlwood et al., 2003) thus enhancing disease transmission by increasing the frequency of contact with hosts (Garrett-Jones, 1964; Garrett-Jones and Shidrawi, 1969; Dye, 1986).

From a forensic perspective, human blood found in the digestive tract of mosquitoes can support investigations of crimes committed in closed environments, i.e., in a room or a vehicle (Spitaleri et al., 2006; Curic et al., 2014). Thus, it is possible that supplementary feeding performed by females in such environments may be allowed for the genetic material of different subjects to be found in a single mosquito. This may elevate the importance of mosquitos as forensic evidence. However, such hypothesis has rarely been investigated.

In addition, due to the wide distribution of mosquitoes, insects found at crime scenes can be an easily accessible source of human genetic material for forensic purposes (Spitaleri et al., 2006). Comparison of the suspect's DNA profile with that of the Scientific Police may also indicate whether a crime is a repeated offense (Wallace et al., 2014), further increasing the importance of mosquitos as a tool of crime investigations.

In this study, we evaluated whether human blood obtained from mosquitos caught at indoor crime scenes could identify the DNA profiles from both the victim and the suspects. The effect of time delay after blood meals was also investigated.

Genetics and Molecular Research 15 (3): gmr.15037547 


\section{MATERIAL AND METHODS}

\section{Obtaining the mosquitoes}

Adult mosquitoes of the Aedes aegypti species were obtained from the Laboratory of Endemics/LACEN (Recife/Pernambuco/Brazil). Confirmation of species identification was performed with the taxonomic key of Rueda (2004). Adult females were kept in cages with $10 \%$ sucrose solution up to $24 \mathrm{~h}$ before blood was supplied.

\section{Obtaining mixture human DNA samples from hematophagous mosquitoes}

Ten mosquitoes were placed in each cage, and identified according to the time interval after blood meal $(24,48$ and $72 \mathrm{~h})$ as well as their respective volunteer that provided the blood mixture. The volunteers were identified by the letters A (woman), B (man), C (woman), and D (woman) and they exposed their arms in the cages for the mosquitoes to feed upon (Table 1). Hematophagy from each volunteer was used as a control group. Before hematophagy by female mosquitoes, the arms of volunteers were washed with water and mild soap. None of the donors wore perfumes in order to avoid the presence of attractive or repellent scents for mosquitoes.

Table 1. Order of display of volunteer arms and blood meal time.
\begin{tabular}{l|c}
\hline Order of display of volunteer arms in the cage & Time/each volunteer (in seconds) \\
\hline A-C & 30 \\
\hline A-B-C & 20 \\
\hline B-D-A-C & 15 \\
\hline
\end{tabular}

One at a time, an arm of each individual was exposed in the cages to ensure that blood meal was acquired from all volunteers. To avoid any data bias, we established order of arm exposure randomly, as shown in Table 1. After a pre-defined time was reached, the arm was removed. To simulate a hypothetical case: volunteer A was defined as the victim, and the other volunteers (B, C and $\mathrm{D})$ were designated as would be possible suspects.

After completion of the blood feeding, the mosquitoes were sacrificed 24, 48 and 72 $\mathrm{h}$ following the blood meal. The mosquitoes were crushed on filter papers, and subsequent genetic analysis was carried out in the Laboratory of Expertise and Research in Forensic Genetics/Secretary of Social Defense (Recife/Pernambuco/Brazil).

\section{Reference samples}

For sample comparisons, $2 \mathrm{~mL}$ blood from each volunteer was pooled into tubes containing EDTA, in the same order of the blood meal shown in Table 1. This was used as a standard analysis for subsequent comparison with the results of genetic profiles obtained from the digestive tract blood of hematophagous mosquitoes. Furthermore, reference samples were collected from oral mucosa of all volunteers.

\section{Human DNA extraction}

DNA samples were extracted using the DNA IQ ${ }^{\mathrm{TM}}$ System kit (Promega, Madison, 
WI, USA) following the manufacturer protocols.

\section{Genetic analysis}

DNA quantification was performed using the Quantifiler ${ }^{\circledR}$ Duo DNA Quantification kit (Applied Biosystems, Foster City, CA, USA) with the Real-Time PCR ABI 7500 platform. Genetic profiling for 15 STR loci (D8S1179, D21S11, D7S820, CSF1PO, D3S1358, THO1, D13S317, vWA, TPOX, D18S51, D5S818, D16S539, Penta D, Penta E, and FGA) and amelogenin was achieved by using the PowerPlex ${ }^{\circledR}$ HS System (Promega) following the manufacturer protocols.

\section{Ethics approval}

This study was approved by the Ethics Committee of the Universidade Federal de Pernambuco (Recife/Brazil) under protocol number 462/11.

\section{Statistical analyses}

The DNA Mix v. 3.2 software was used for the statistical analysis to calculate the likelihood ratios (Curran et al., 1999) of the sample mixture with genetic profiles. An ancestry coefficient of 0.01 and minimum frequency of 0.01 was used in a database of allelic frequencies of a Brazilian population (Aguiar et al., 2012) with a confidence interval of 95\%. For each cage, we have the following list of samples for statistical analysis simulating a hypothetical case: mosquito mixture containing human DNA considered as trace (questioned sample); victim's sample corresponding to the volunteer A DNA; and the other volunteers (B, C, and D) would be possible suspects.

\section{RESULTS AND DISCUSSION}

We obtained the genetic profiles for three and four mixed samples from a single mosquito $24 \mathrm{~h}$ following the blood meal. However, we did not obtain viable results from mixtures found in mosquitos 48 and $72 \mathrm{~h}$ following hematophagy. Moreover, we also did not obtain profiles for two mixed samples after $24 \mathrm{~h}$, as we could only visualize the profile of one donor.

The quantification analysis showed that $0.019 \mathrm{ng} / \mu \mathrm{L}$ human DNA was obtained from one individual; $0.010 \mathrm{ng} / \mu \mathrm{L}$ male DNA when three individuals were used, and $0.256 \mathrm{ng} / \mu \mathrm{L}$ human DNA (0.007 ng/ $\mu \mathrm{L}$ of male DNA) when four individuals were used. The value of statistical analysis of likelihood ratio (LR) was defined as association of the genetic profile found in the mixture to an individual in the population. The LR value was calculated in relation to only the complete markers. Therefore, for statistical comparison of traces with two suspects (B and C), the following loci were excluded: Penta E, D16S539, TPOX, and FGA; and calculations with three possible suspects (B, C and D) THO1, Penta E, and D5S818 were excluded. The resulting LRs were $3.2 \times 10^{12}$ and $128.3 \times 10^{12}$ for mixtures from three or four individuals, respectively. This calculation is widely used in forensic interpretations (Ladd et al., 2001; Gill et al., 2006; Haned et al., 2015).

The reference patterns obtained in in vitro mixtures of the blood provided comparable

Genetics and Molecular Research 15 (3): gmr.15037547 
profiles. If one compares the peaks in Figure 1A and B with the profiles from the mosquitos' mixed blood and the reference profile, respectively, only two alleles were missing: allele 8 from THO1 and allele 10 from Penta E. Alleles 7 and 12 had lower peaks due to their base pair sizes. It is also important to bear in mind that these positive results were obtained $24 \mathrm{~h}$ after the hematophagy event, which corresponded to the time period during which the mosquito started to metabolize blood for posterior oviposition (Spitaleri et al., 2006).

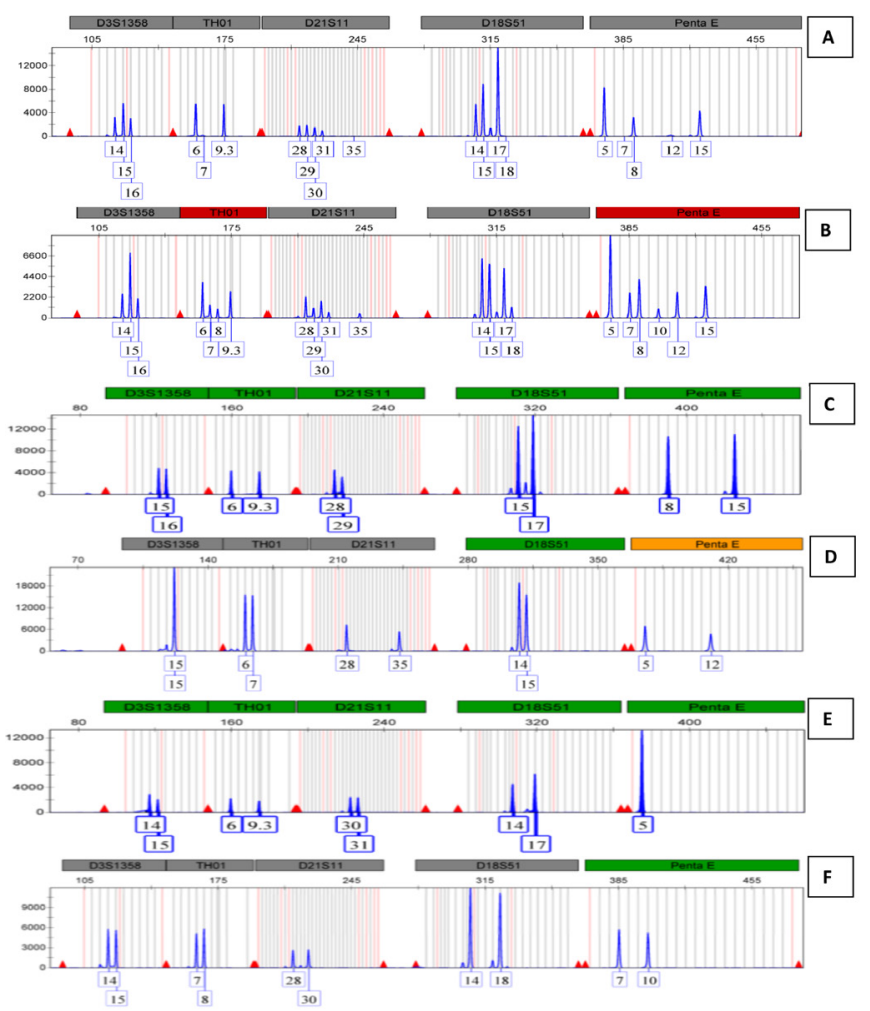

Figure 1. Comparison of human DNA profiles with loci D3S1358, THO1, D21S11, D18S51, and Penta E. A. Mixture profile trace showing the profiles of four volunteers with blood obtained from the digestive tract of the mosquito Aedes aegypti $24 \mathrm{~h}$ after hematophagy. B. Standard mixture profile of blood from the four volunteers. C. Profile simulating the victim (corresponding to the volunteer A). D.-F. Profiles of possible suspects (corresponding to the volunteers B, C and D, respectively).

For the loci D5S818, D13S317, D7S820, D16S539, CSF1PO, and Penta D shown in Figure 2A-F, we observed that all alleles were obtained when the sample trace profiles were compared with the reference samples.

For analysis of the markers vWa, D8S1179, TPOX, and FGA (Figure 3A-F), some alleles had low peaks. We expected disproportionality in amelogenin, with $\mathrm{X}$ allele donor being greater than $\mathrm{Y}$ alleles, as the donor material was from three women but only one man. This was observed in alleles 23 and 25 on the marker FGA, which were expressed at a low to medium level. Such markers require a greater number of base pairs, especially as these alleles are expressed in a man. 


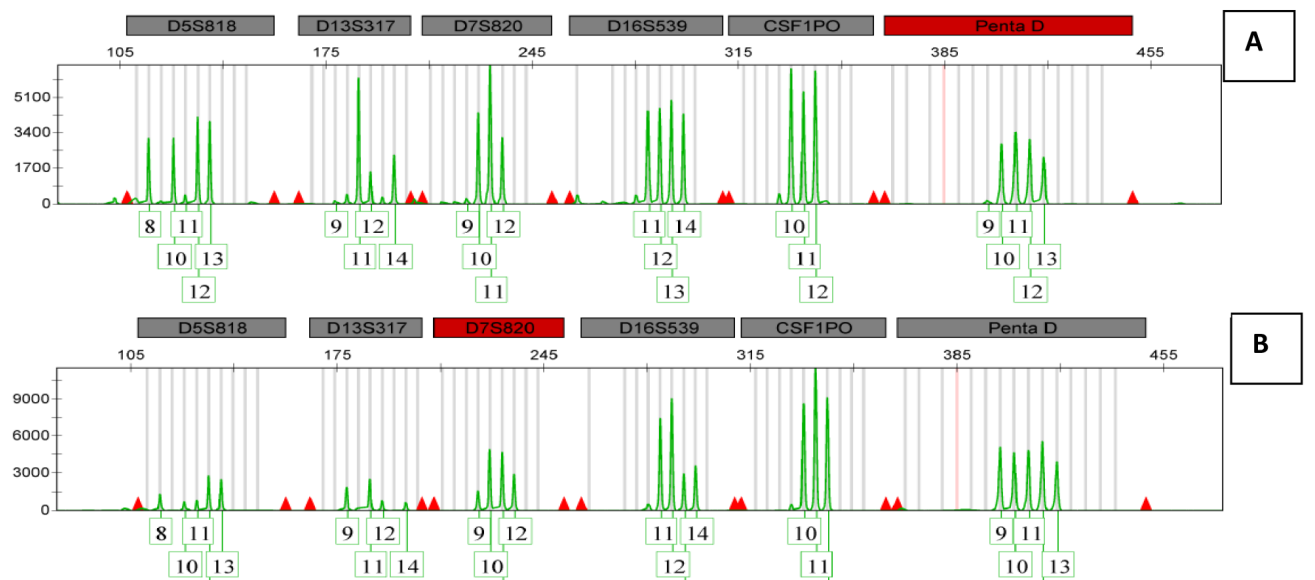

12

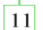

13

12

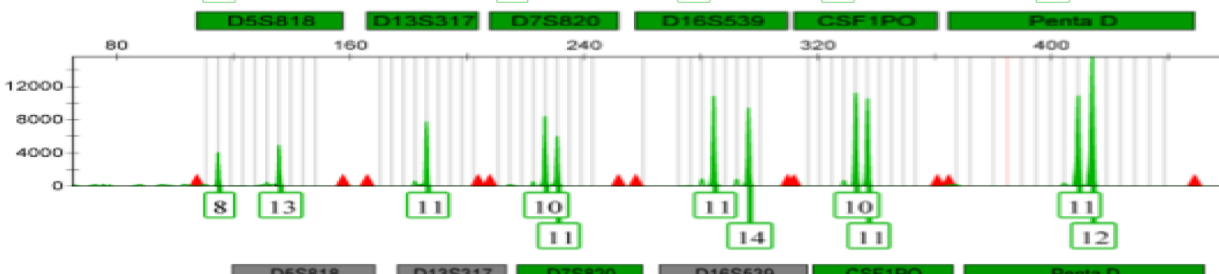

C

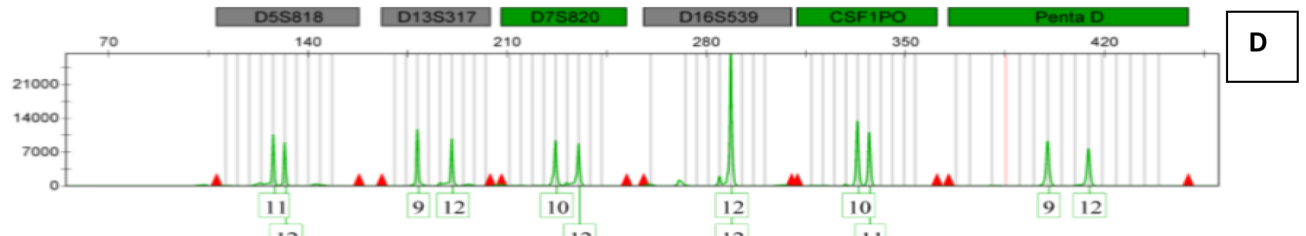

12

$12 \quad 11$
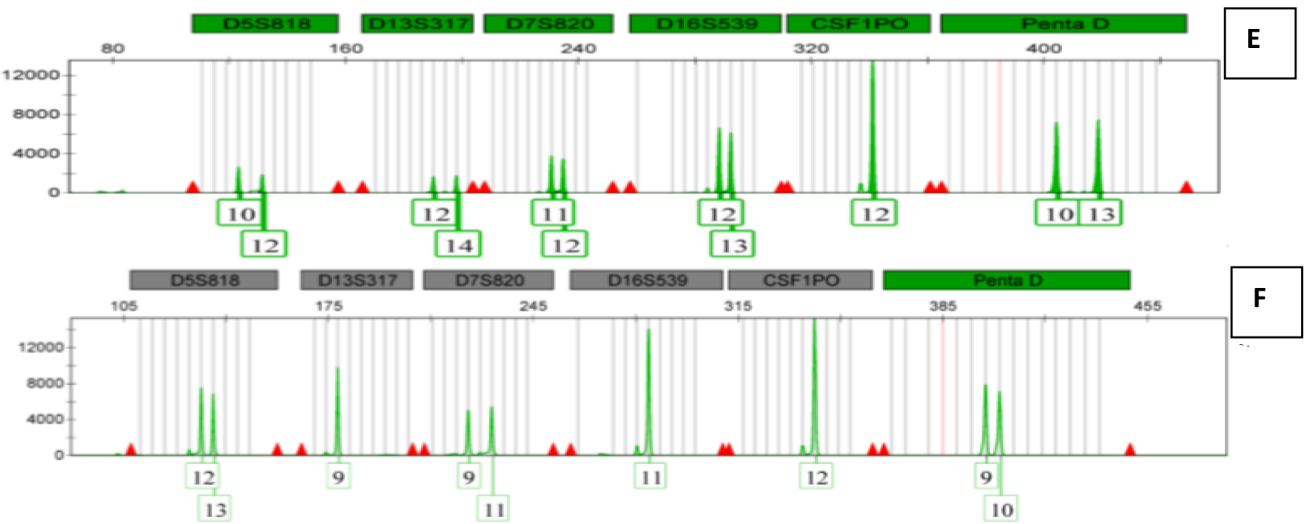

Figure 2. Comparison of human DNA profiles with loci D5S818, D13S317, D7S820, D16S539, CSF1PO, and Penta D. A. Mixture profile trace showing the profiles of the four volunteers with blood obtained from the digestive tract of the mosquito Aedes aegypti $24 \mathrm{~h}$ after hematophagy. B. Standard mixture profile of blood from the four volunteers. C. Profile simulating the victim (corresponding to the volunteer A). D.-F. Profiles of possible suspects (corresponding to the volunteers $\mathrm{B}, \mathrm{C}$ and $\mathrm{D}$, respectively).

Genetics and Molecular Research 15 (3): gmr.15037547 


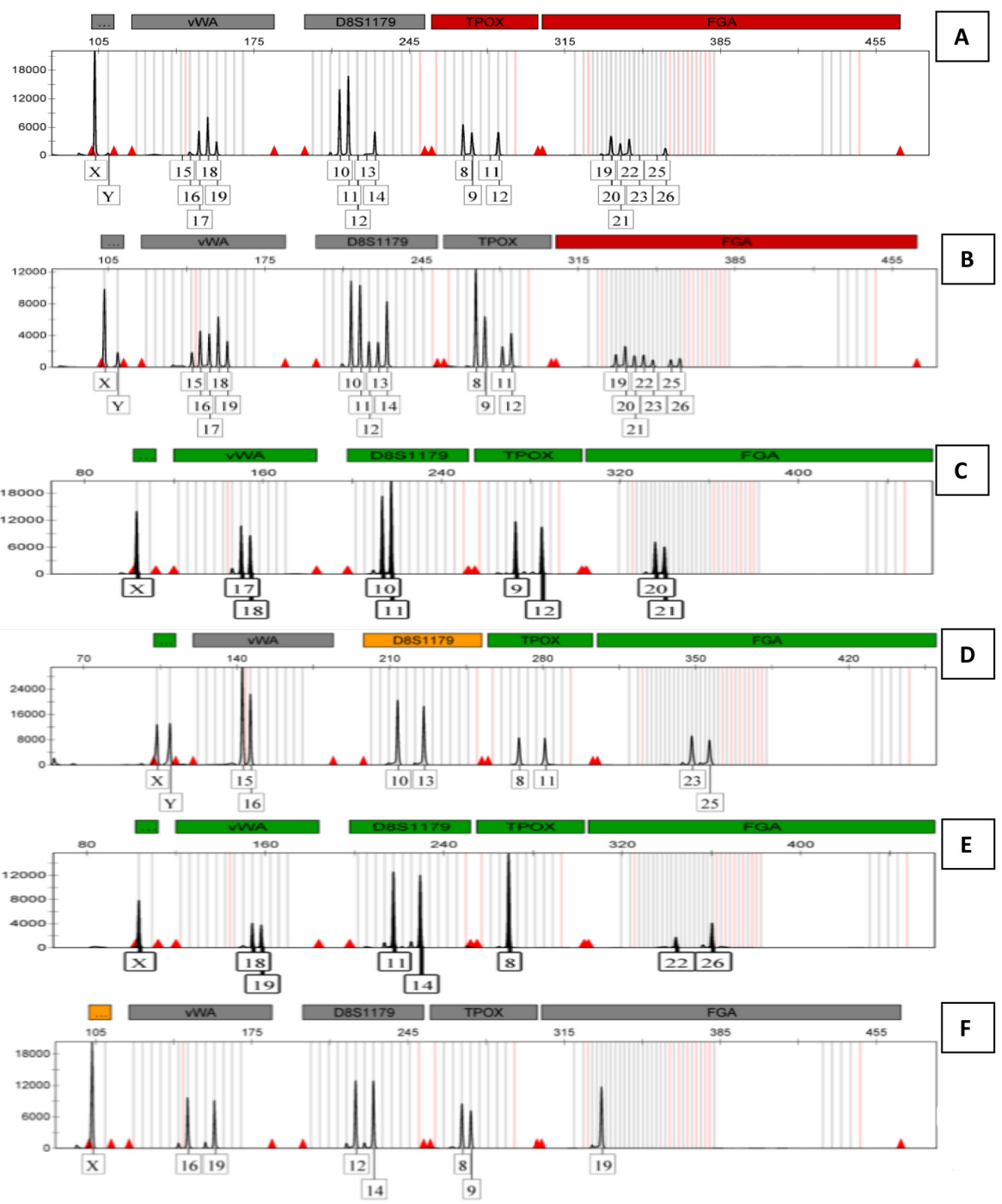

Figure 3. Comparison of human DNA profiles with loci vWA, D8S1179, TPOX, FGA, and amelogenin. A. Mixture profile trace showing the profiles of four volunteers with blood obtained from the digestive tract of the mosquito Aedes aegypti $24 \mathrm{~h}$ after hematophagy. B. Standard mixture profile of blood from the four volunteers. C. Profile simulating the victim (corresponding to the volunteer A). D.-F. Profiles of possible suspects (corresponding to the volunteers $\mathrm{B}, \mathrm{C}$ and $\mathrm{D}$, respectively).

In the 15 STR loci analyzed, in addition to the sexual marker amelogenin, all values were greater than that recommended by FBI for the implementation of Combined DNA Index System (CODIS). This system, composed of 13 STR loci, has become a reference for other countries regarding forensic analysis, and the larger the number of studied loci, the greater the reliability for the comparison between sample and the reference traces (Budowle et al., 1999; Sun et al., 2003). 
Absence of alleles is also commonly found in sample mixtures. Traces at the crime scene are obtained from inanimate objects, such as bottles, as well from living organisms such as mosquitoes and necrophagous larvae. Mixed and degraded samples offer forensic challenge due to imbalanced peaks and limited expression of one or more alleles (Ladd et al., 2001). Even with the failure to obtain matching alleles between full-profile of the suspect and evidentiary sample, the profile trace mixture may be essential for other aspects of the case, such as including or excluding suspects (Butler, 2005).

In crime scenes it is common for researchers to collect traces that, after analysis, are identified as mixtures containing human DNA. We show that biological traces with mixed genetic profiles, such as in hematophagous mosquitoes, may be important for inclusion or exclusion of suspects, and aid crime investigations.

\section{Conflicts of interest}

The authors declare no conflict of interest.

\section{ACKNOWLEDGMENTS}

We thank the Laboratory of Immunopathology Keizo Asami (Recife/Pernambuco/ Brazil), the Laboratory of Endemics/LACEN (Recife/Pernambuco/Brazil), and the Expertise and Research Laboratory in Forensic Genetics/Secretary of Social Defense (Recife/ Pernambuco/Brazil) for laboratory support. Thanks also the volunteers in this study.

\section{REFERENCES}

Aguiar VR, Wolfgramm EdeV, Malta FSV, Bosque AG, et al. (2012). Updated Brazilian STR allele frequency data using over 100,000 individuals: an analysis of CSF1PO, D3S1358, D5S818, D7S820, D8S1179, D13S317, D16S539, D18S51, D21S11, FGA, Penta D, Penta E, TH01, TPOX and vWA loci. Forensic Sci. Int. Genet. 6: 504-509. http:// dx.doi.org/10.1016/j.fsigen.2011.07.005

Amerasinghe PH and Amerasinghe FP (1999). Multiple host feeding in field populations of Anopheles culicifacies and An. subpictus in Sri Lanka. Med. Vet. Entomol. 13: 124-131. http://dx.doi.org/10.1046/j.1365-2915.1999.00160.x

Attardo GM, Hansen IA and Raikhel AS (2005). Nutritional regulation of vitellogenesis in mosquitoes: implications for anautogeny. Insect Biochem. Mol. Biol. 35: 661-675. http://dx.doi.org/10.1016/j.ibmb.2005.02.013

Boreham PF and Garrett-Jones C (1973). Prevalence of mixed blood meals and double feeding in a malaria vector (Anopheles sacharovi Favre). Bull. World Health Organ. 48: 605-614.

Budowle B, Moretti TR, Baumstark AL, Defenbaugh DA, et al. (1999). Population data on the thirteen CODIS core short tandem repeat loci in African Americans, U.S. Caucasians, Hispanics, Bahamians, Jamaicans, and Trinidadians. $J$. Forensic Sci. 44: 1277-1286. http://dx.doi.org/10.1520/JFS14601J

Burkot TR, Graves PM, Paru R and Lagog M (1988). Mixed blood feeding by the malaria vectors in the Anopheles punctulatus complex (Diptera: Culicidae). J. Med. Entomol. 25: 205-213. http://dx.doi.org/10.1093/jmedent/25.4.205

Butler JM (2005). Forensic DNA typing: Biology, technology and genetics of STR markers. 2nd edn. Elsevier Academic Press, 660.

Clements AN (1999). The Biology of Mosquitoes: Sensory, Reception, and Behaviour. 2nd edn. CABI Publishing, Cambridge.

Charlwood JD, Pinto J, Sousa CA, Ferreira C, et al. (2003). 'A mate or a meal'--pre-gravid behaviour of female Anopheles gambiae from the islands of São Tomé and Príncipe, West Africa. Malar. J. 2: 9. http://dx.doi.org/10.1186/1475$\underline{2875-2-9}$

Conway DJ and McBride JS (1991). Genetic evidence for the importance of interrupted feeding by mosquitoes in the transmission of malaria. Trans. R. Soc. Trop. Med. Hyg. 85: 454-456. http://dx.doi.org/10.1016/00359203(91)90217-M

Genetics and Molecular Research 15 (3): gmr.15037547 
Curic G, Hercog R, Vrselja Z and Wagner J (2014). Identification of person and quantification of human DNA recovered from mosquitoes (Culicidae). Forensic Sci. Int. Genet. 8: 109-112. http://dx.doi.org/10.1016/j.fsigen.2013.07.011

Curran JM, Triggs CM, Buckleton J and Weir BS (1999). Interpreting DNA mixtures in structured populations. J. Forensic Sci. 44: 987-995. http://dx.doi.org/10.1520/JFS12028J

Delatte H, Desvars A, Bouétard A, Bord S, et al. (2010). Blood-feeding behavior of Aedes albopictus, a vector of Chikungunya on La Réunion. Vector Borne Zoonotic Dis. 10: 249-258. http://dx.doi.org/10.1089/vbz.2009.0026

Dye C (1986). Vectorial capacity: must we measure all its components? Parasitol. Today (Regul. Ed.) 2: 203-209. http:// dx.doi.org/10.1016/0169-4758(86)90082-7

Edman JD and Downe ERA (1964). Host-blood sources and multiple-feeding habits of mosquitoes in Kansas. Mosq. News 24: $154-160$

Garrett-Jones C (1964). Prognosis for interruption of malaria transmission through assessment of the mosquito's vectorial capacity. Nature 204: 1173-1175. http://dx.doi.org/10.1038/2041173a0

Garrett-Jones C and Shidrawi GR (1969). Malaria vectorial capacity of a population of Anopheles gambiae: an exercise in epidemiological entomology. Bull. World Health Organ. 40: 531-545.

Gill P, Brenner CH, Buckleton JS, Carracedo A, et al.; DNA commission of the International Society of Forensic Genetics (2006). DNA commission of the International Society of Forensic Genetics: Recommendations on the interpretation of mixtures. Forensic Sci. Int. 160: 90-101. http://dx.doi.org/10.1016/j.forsciint.2006.04.009

Haned H, Benschop CC, Gill PD and Sijen T (2015). Complex DNA mixture analysis in a forensic context: evaluating the probative value using a likelihood ratio model. Forensic Sci. Int. Genet. 16: 17-25. http://dx.doi.org/10.1016/j. fsigen.2014.11.014

Harrington LC, Fleisher A, Ruiz-Moreno D, Vermeylen F, et al. (2014). Heterogeneous feeding patterns of the dengue vector, Aedes aegypti, on individual human hosts in rural Thailand. PLoS Negl. Trop. Dis. 8: e3048. http://dx.doi. org/10.1371/journal.pntd.0003048

Ladd C, Lee HC, Yang N and Bieber FR (2001). Interpretation of complex forensic DNA mixtures. Croat. Med. J. 42: 244-246.

Reyes-Villanueva F (2004). Egg development may require multiple bloodmeals among small Aedes aegypti (Diptera: Culicidae) field collected in northeastern Mexico. Fla. Entomol. 87: 630-632. http://dx.doi.org/10.1653/00154040(2004)087[0630:EDMRMB]2.0.CO;2

Rueda LM (2004). Pictorial keys for the identification of mosquitoes (Diptera: Culicidae) associated with Dengue Virus Transmission. Zootaxa 589: 1-60.

Scott TW and Takken W (2012). Feeding strategies of anthropophilic mosquitoes result in increased risk of pathogen transmission. Trends Parasitol. 28: 114-121. http://dx.doi.org/10.1016/j.pt.2012.01.001

Scott TW, Chow E, Strickman D, Kittayapong P, et al. (1993a). Blood-feeding patterns of Aedes aegypti (Diptera: Culicidae) collected in a rural Thai village. J. Med. Entomol. 30: 922-927. http://dx.doi.org/10.1093/jmedent/30.5.922

Scott TW, Clark GG, Lorenz LH, Amerasinghe PH, et al. (1993b). Detection of multiple blood feeding in Aedes aegypti (Diptera: Culicidae) during a single gonotrophic cycle using a histologic technique. J. Med. Entomol. 30: 94-99. http://dx.doi.org/10.1093/jmedent/30.1.94

Scott TW, Amerasinghe PH, Morrison AC, Lorenz LH, et al. (2000). Longitudinal studies of Aedes aegypti (Diptera: Culicidae) in Thailand and Puerto Rico: blood feeding frequency. J. Med. Entomol. 37: 89-101. http://dx.doi. org/10.1603/0022-2585-37.1.89

Spitaleri S, Romano C, Di Luise E, Ginestra E, et al. (2006). Genotyping of human DNA recovered from mosquitoes found on a crime scene. Int. Cong. Ser. 1288: 574-576.

Sun G, McGarvey ST, Bayoumi R, Mulligan CJ, et al. (2003). Global genetic variation at nine short tandem repeat loci and implications on forensic genetics. Eur. J. Hum. Genet. 11: 39-49. http://dx.doi.org/10.1038/sj.ejhg.5200902

Wallace HM, Jackson AR, Gruber J and Thibedeau AD (2014). Forensic DNA databases - ethical and legal standards: a global review. Egypt J. Forensic Sci. 4: 57-63. http://dx.doi.org/10.1016/j.ejfs.2014.04.002

Xue RD, Edman JD and Scott TW (1995). Age and body size effects on blood meal size and multiple blood feeding by Aedes aegypti (Diptera: Culicidae). J. Med. Entomol. 32: 471-474. http://dx.doi.org/10.1093/jmedent/32.4.471

Genetics and Molecular Research 15 (3): gmr.15037547 